\title{
LES PSEUDONYMES DE KAZIMIERZ BRANDYS
}

\author{
Agnieszka GRUDZIŃSKA (Sorbonne Université)
}

\author{
« $\mathrm{Si}$ j'écrivais mon autobiographie, je l'intitulerais \\ 'Histoire d'un adjectif' ". \\ Isaac Babel ; cité en exergue au Juif imaginaire \\ d'Alain Finkielkraut \\ «- Gentlemen, veuillez écouter le gars qui a failli être \\ transformé en savon, entrée libre $»^{1}$. \\ Kazimierz Brandys, La Place du marché
}

Figure de proue de la littérature polonaise, Kazimierz Brandys, auteur de romans, récits, essais, pièces de théâtre et scénarios, né à Łódź en 1916 dans une famille d'origine juive assimilée, est mort en 2000 à Paris, où il vivait depuis 1981. La critique française n'hésite pas à le considérer comme l'un des plus grands écrivains polonais du $\mathrm{XX}^{\mathrm{e}}$ siècle. Son œuvre, largement traduite, embrasse les formes narratives les plus diverses et témoigne des vicissitudes de l'histoire de la Pologne: la guerre, l'expérience du communisme, l'opposition au système autoritaire, ou encore l'exil. Son itinéraire, tant artistique que biographique, peut être considéré comme emblématique de cette génération d'artistes et d'intellectuels polonais aux racines juives qui composent avec leur double identité tout au long de leur vie.

Une revue des œuvres successives de Brandys - écrit Agnieszka Czyżak, qui lui a consacré une monographie - peut également constituer une revue des étapes de la formation de la prose contemporaine, un condensé de l'histoire de la littérature de l'aprèsguerre. Depuis les règlements de comptes de l'intelligentsia [avec le passé d'avant-guerre, terme de Kazimierz Wyka] jusqu'au roman-journal et au journal-essai en passant par le réalisme socialiste, par la prose des règlements de comptes de l'après-octobre 1956 [il

1 „- gentlemeni, raczcie wysłuchać faceta, którego o mało nie przerobili na mydło, wstęp wolny”. K. B. Rynek, Varsovie 1994, p. 136. 
s'agit de « la prose du dégel »], par les expérimentations [formelles] des années 1960, les œuvres d'autofiction et les récits placés sous le signe de la stylisation et du pastiche $[\ldots]^{2}$.

Kazimierz Brandys passe son baccalauréat et fait ses études à Varsovie. Il y est témoin - et parfois victime - des exactions de la droite nationaliste. Il obtient son diplôme de droit en 1939. Pendant la guerre, il décide de ne pas se laisser enfermer dans le ghetto. Il lui faut donc cacher ses origines. Son père refuse également de porter le brassard blanc avec l'étoile bleue. L'écrivain passe la période de l'Occupation à Varsovie du côté aryen, avec de faux papiers d'identité au nom de Borowiecki, en évitant de justesse à plusieurs reprises d'être dénoncé comme Juif ${ }^{3}$.

Au sortir de la guerre, il adhère au Parti communiste et, de 1946 à 1956, il est le vice-président de l'Union des écrivains polonais. Il collabore également à la revue Kuźnica puis à Nowa Kultura. Son premier roman, publié un an après la guerre, Le cheval de bois [Drewniany koń] est considéré comme l'un des « romans de règlement de comptes de l'intelligentsia » avec la réalité politique et sociale de la Pologne de l'entre-deux-guerres («rozrachunki/obrachunki inteligenckie ») ${ }^{4}$, pour reprendre les mots du critique Kazimierz Wyka.

Comme pour nombre d'autres intellectuels, commence ensuite pour lui la période de l'engagement fervent pour l'idéal (et la pratique) communiste. S'il publie des livres sur l'Occupation nazie, où le ton sonne juste (Warszawa, miasto niezłomne, 1946 [Varsovie, ville invincible], réédité treize fois, prix de la ville de Varsovie, ainsi que Samson en 1948), c'est essentiellement comme membre du Parti qu'il s'exprime dans ses premiers écrits, construits pour la plupart selon les canons du réalisme socialiste. Pendant dix années, l'idéologie communiste domine son œuvre, essentiellement composée, d'une part, de la tétralogie Między wojnami, (1946-1951) [Entre les guerres], qui rassemble Samson, Antigone, Troja, miasto otwarte [Troie, ville ouverte] et Człowiek nie umiera [L'homme ne meurt pas] et, d'autre part, du roman réaliste socialiste Obywatele, 1954 [Citoyens], prix national. Le texte Nim będzie zapomniany ${ }^{5}$ [Avant qu'il ne soit oublié], pamphlet féroce contre un artiste peintre fictif du nom de Wejmont, dans lequel on pouvait aisément reconnaître Czesław Miłosz, écrit après que celui-ci eut quitté la Pologne, donne la mesure de l'état d'esprit de Brandys pendant cette période sombre de la culture polonaise ${ }^{6}$. Certains critiques souligneront plus tard

2 „Przegląd kolejnych utworów Brandysa stanowić może zarazem przegląd etapów kształtowania się prozy najnowszej, historię literatury powojennej 'w pigułce'. Od obrachunków inteligenckich, poprzez socrealizm, październikową prozę rozrachunkową, eksperymenty lat sześćdziesiatych, kreacje autopowieściowe, utwory spod znaku stylizacji i pastiszu, aż do dziennikapowieści i dziennika-eseju [...]”. A. Czyżak, Kazimierz Brandys, Poznań 1998, p.6. (Sauf mention contraire, les traductions sont de l'auteur de l'article).

${ }^{3}$ Sa future femme Maria, née Zenowicz, (historienne de l'art, plus tard traductrice entre autres de Camus et de Robbe-Grillet) l'y aida grandement, notamment en " arrangeant » leur mariage catholique.

${ }^{4}$ À part le roman de Brandys, entrent dans cette catégorie : Sprzysiężenie [Conjuration], 1947, de Stefan Kisielewski, Jezioro Bodeńskie [Le lac de Constance], 1946, de Stanisław Dygat et Sedan, 1948, de Paweł Hertz.

${ }^{5}$ Publié dans Nowa Kultura 1955 n ${ }^{\circ}$ 38, repris dans Czerwona czapeczka [Le bonnet rouge], Varsovie 1956 et 1957.

${ }^{6}$ Brandys a nié jusqu'à la fin de sa vie qu'il s'agissait de Miłosz. Cf. A. Bikont, J. Szczęsna, Lawina i kamienie. Pisarze wobec komunizmu [L'avalanche et les pierres. Les écrivains face au communisme], Varsovie 2006. D'autres écrivains ont également eu de telles réactions au départ 
un opportunisme certain, d'autres verront dans son engagement pour le nouvel ordre le résultat de son expérience de l'entre-deux-guerres et de la guerre, et notamment l'importance qu'a eue pour lui la victoire de l'armée soviétique sur le nazisme ${ }^{7}$, argument fréquent chez les intellectuels de gauche d'Europe orientale comme d'Europe occidentale.

Comme pour beaucoup d'intellectuels de sa génération, le réveil vient avec le dégel de 1956. Les romans du Brandys de cette période (Obrona "Grenady » (1956) [La défense du théâtre "Grenade»], Matka Królów" (1957) [La mère des Król]) appartiennent au courant connu sous le nom de « règlement de comptes », cette fois-ci avec le passé stalinien (literatura rozrachunkowa). Bien que simplistes et toujours schématiques - même si le schéma idéologique des récits réalistes socialistes est inversé) - ces romans constituent indéniablement un tournant significatif dans le cheminement artistique de Brandys. En effet, la perspective sociologique et historique — au sens marxiste - cède la place à l'analyse psychologique, existentielle et à la réflexion sur la complexité du destin de l'homme libéré des contraintes idéologiques. Deux textes témoignent tout particulièrement de cette nouvelle dynamique créatrice. Dans le premier, Wywiad z Ballmeyerem (1959) [L'interview de Ballmeyer], Brandys mène une fine analyse du mal qu'apporte la guerre. Le récit, réalisé à partir de l'histoire — fictive ? - d'un journaliste américain qui interviewe un criminel nazi, explore, cas fréquent chez l'écrivain, les liens entre l'histoire individuelle et l'histoire collective. Le second, la nouvelle Jak być kochana (1960) [L'art d'être aimée ${ }^{10}$ ], est une vision originale d'un couple pris dans la tourmente de l'Occupation nazie. C'est aussi le portrait fascinant d'une femme prête à tout sacrifier pour sauver «son homme » et qui en paie le prix fort. C'est également une analyse perspicace de la difficulté à prendre des décisions dans des circonstances extrêmes, décisions qu'il serait imprudent de juger à l'aune d'une quelconque morale. Quant à la forme de ce récit-patchwork à la temporalité fantaisiste ${ }^{11}$, elle confirme la rupture de Brandys avec le roman traditionnel.

Les années 1960 et 1970 sont très fructueuses pour l'écrivain, qui continue à explorer de nouvelles formes hybrides de narration. Il faut mentionner Dżoker (1966) [Le joker], Rynek (1968) [La place du marché], et Mała ksiegga (1970) [Le petit livre], mais c'est avant tout Wariacje pocztowe (1972) [Variations postales], qui attirent

de Miłosz, cf. les textes de Jarosław Iwaszkiewicz et d'Antoni Słonimski, ainsi que Poemat dla zdrajcy [Poème pour un traître], de Konstanty Ildefons Gałczyński.

${ }^{7}$ Cf. le chapitre sur Brandys dans Lawina i kamienie [L'avalanche et les pierres], intitulé Ocalony przez Armię Czerwona, czyli Kazimierz Brandys jest za, [Sauvé par l'Armée rouge, ou Kazimierz Brandys se prononce pour], p. 44-55.

${ }^{8}$ Publié dans le numéro spécial des Temps Modernes février-mars $1957 \mathrm{n}^{\circ} 132-133$, qui est consacré au «socialisme polonais», avec les textes d'autres «écrivains du dégel»: Adam Ważyk, Wiktor Woroszylski, Jerzy Andrzejewski...

${ }^{9}$ Cf. La mère des rois, La défense de Grenade, Paris, 1958, trad. fr. V. Achères. Le roman La mère des rois a été porté à l'écran en 1982 par Janusz Zaorski ; le film a obtenu de nombreux prix internationaux. Il n'a pu être diffusé en Pologne qu'en 1987.

${ }^{10}$ L'art d'être aimée et autres nouvelles, trad. fr. Gabriel Mérétik et Christophe Potocki, Paris 1993. Ce texte a servi de scénario au film réalisé en 1963 par Wojciech Has et retenu pour la sélection officielle du festival de Cannes de la même année.

${ }^{11}$ Il est à noter que le titre de la plupart d'ouvrages de Brandys est suivi de la mention « souvenirs du temps présent» [wspomnienia z teraźniejszości]. 
l'attention tant de la critique que des lecteurs ${ }^{12}$. Ce roman épistolaire ${ }^{13}$ s'étend sur deux cents ans : les premières lettres datent de 1770 et les dernières de 1970. On y trouve un pastiche magistral du style de chaque époque ${ }^{14}$. Brandys y donne une vision de l'histoire de la Pologne étonnante par sa perspicacité amère. La prévisibilité des destins des membres de la famille Zabierski - la dernière lettre, restée sans réponse, constitue une référence voilée aux événements de 1968 - donne à réfléchir sur le mécanisme de création des mythes collectifs polonais, sujet préféré de Brandys ${ }^{15}$. C'est également un de ces récits dans lesquels les éléments autobiographiques, et notamment les liens polono-juifs, apparaissent par petites touches, certes discrètes mais toujours essentielles.

\section{La vie est ailleurs}

C'est sans doute également sous la pression des événements que la réalité prend le pas sur la fiction dans l'œuvre de Brandys. En signe de protestation contre les critiques émises à l'encontre du philosophe Leszek Kołakowski, l'écrivain quitte le Parti communiste en 1966. En 1976, il est l'un des signataires du Manifeste des 101 [Memoriat 101], adressé aux autorités et dans lequel les intellectuels s'opposaient au projet de modification constitutionnelle, qui prévoyait de mentionner dans la Loi fondamentale polonaise «le rôle dirigeant du POUP» [Parti ouvrier unifié polonais, Polska Zjednoczona Partia Robotnicza] ainsi que le «lien durable et la fidélité à l'URSS $»^{16}$.

Dans la deuxième moitié des années 1970, Brandys se lie avec le Comité de défense des ouvriers [Komitet Obrony Robotników (KOR)], mouvement d'opposition fondé par des intellectuels. La période de sa vie où il était le « chouchou du régime » prend définitivement fin. Il collabore désormais à Zapis, revue littéraire clandestine. Il publie ses ouvrages chez NOWA, maison d'édition clandestine. C'est notamment le cas

${ }^{12} \mathrm{Cf}$. le recueil d'articles consacré à ce livre, Wariacje pocztowe Kazimierza Brandysa [Variations postales de Kazimierz Brandys], I. Iwasiów, J. Madejski (dir.), Szczecin 1999. Voir par ailleurs un livre très complet sur l'œuvre de Brandys, celui de M. Wołk, Tekst $w$ dwóch kontekstach. Narracja pierwszoosobowa w powieściach Kazimierza Brandysa [Le texte dans les deux contextes. La narration à la première personne dans les romans de Kazimierz Brandys], Toruń 1999.

13 Brandys s'était déjà exercé à ce genre avec ses lettres-essais, Listy do pani Z. (1958) ; Lettres à Mme Z., souvenirs du temps présent, trad. fr. A. Posner, Paris 1961.

${ }_{14}$ Bien entendu, ce pastiche ne constitue pas seulement une convention littéraire et un exercice de style, mais il permet surtout de mener une polémique avec le monde ainsi parodié. Cf. R. Nycz, Parodia i pastisz. $Z$ dziejów pojęć artystycznych $w$ świadomości literackiej $X X$ wieku. Uwagi o pastiszu [Parodie et pastiche. L'histoire des notions artistiques dans la conscience littéraire du XX $X^{e}$ siècle. Remarques sur le pastiche], [in :] R. Nycz, Tekstowy świat. Poststrukturalizm a wiedza o literaturze [Un monde de textes. Le post-structuralisme et la connaissance de la littérature], Cracovie 2000, p. 229-240.

${ }^{15} \mathrm{Cf}$. le riche article de Maciej Chojnowski consacré à cet ouvrage, Historia jako beletrystyka czasu - Kazimierza Brandysa zmagania z przeszłościa [L'histoire comme littérature du temps. Kazimierz Brandys aux prises avec le passé], [in :] Pisarze polsko-żydowscy XX wieku. Przybliżenia [Les écrivains polono-juifs du XX siècle. Approches], M. Dąbrowski, A. Molisak (dir.), Varsovie 2006, p. 200-212.

${ }^{16}$ La modification fut adoptée par la Diète. Un seul député vota contre, Stanisław Stomma, du groupe ZNAK (catholique). 
de Nierzeczywistość [l'Irréalité], publié en $1977^{17}$. C'est aussi le cas de son journalessai Miesiace $[\text { Mois }]^{18}$, publié en 1980. Ses ouvrages sont également édités par l'Institut littéraire Kultura, maison d'édition de l'émigration polonaise à MaisonsLaffitte. En renonçant à se plier au diktat de la censure, il se condamne à une nonexistence officielle. Il partage le sort d'autres intellectuels qui ont pris ce chemin : son nom est banni et ses livres, proscrits du « réseau officiel » des bibliothèques, librairies, programmes scolaires, etc. circulent uniquement, en tirage très limité, "sous le manteau », dans « le réseau parallèle » (drugi obieg) ${ }^{19}$.

Pendant les seize mois de l'existence légale de Solidarność, la Pologne vit dans l'euphorie son «festival de liberté ». Brandys et sa femme partent début décembre 1981 aux États-Unis. Se trouvant à New York le 13 décembre 1981, date de la proclamation de l'état de siège en Pologne, l'écrivain ne rentre pas dans son pays. À partir de 1983, les Brandys vivent à Paris, dans le Marais.

C'est donc en France que l'écrivain continue à rédiger et à publier ses Carnets. Deux autres récits, Zapamiętane (1995) [De mémoire.... ${ }^{20}$ et Przygody Robinsona (1999) [Les aventures de Robinson] s'inscrivent dans la continuité de ses publications antérieures. Ni journaux, ni mémoires, ni documents, ni fiction, mais plutôt tout cela à la fois. Il s'agit d'une œuvre littéraire que l'auteur qualifie de « journal-essai» et où il entreprend un récit libre conduit au gré de sa mémoire. Des livres qui bousculent les frontières des genres admis, participant tout à la fois de la chronique familiale, du documentaire historique, de l'essai sur la mémoire, et de l'art du roman là oú il s'agit d'imaginer tout un passé... Cette forme originale lui permet d'évoquer des thèmes très divers et de passer sans lien apparent de l'insurrection de Varsovie à ses lectures de Vladimir Nabokov, du débat sur la collaboration pendant la période communiste en Pologne à la décadence de la littérature et à son retour à Varsovie - pour y passer ses vacances - après de longues années d'exil en France. Le thème de la famille retrouvée, ainsi que celui du vieillissement et de la maladie sont également amenés d'une manière mi-réelle, mi-fictive. La construction, très libre, permet à l'auteur des rapprochements inattendus et des mises en abyme pour le moins insolites. Comme il le

${ }^{17}$ Premier roman que cet «éditeur » a fait paraître. Titre de la traduction française, En Pologne, c'est-à-dire nulle part, trad. fr. A. Lach, Paris 1978.

${ }^{18}$ C'était la $100^{\mathrm{e}}$ publication de NOW-a. Traduit en français par Carnets.

19 «La revue Zapis, l'Officine éditoriale indépendante [NOWA], les petites imprimeries qui impriment en deux ou cinq mille exemplaires nos livres - tout ne tient qu'à un mince fil. Le soir, j'apprends par téléphone - sur écoutes — que quelqu'un de NOWA a été arrêté. Même si tout se casse, je vais continuer à écrire et je vais taper moi-même à la machine le texte avec trois copies. Ces quatre exemplaires seront lus par quelques dizaines de personnes, quelqu'un va en garder un ou deux. Cette pensée donne des forces pour écrire. Hier, Marian [frère de Kazimierz, auteur de nombreux livres historiques] a appelé en disant qu'une lectrice de Zapis, après avoir lu les Carnets, lui avait remis 1000 zlotys - pour moi. Oh non, je n'échangerais ma place avec personne pour avoir un tirage de masse ». [„,Pismo Zapis, Niezależna Oficyna Wydawnicza, drukarenki powielające nasze książki w dwóch czy pięciu tysiącach egzemplarzy — wszystko wisi na cieniutkim włosku. Wieczorem dowiaduję się przez podsłuchiwany telefon o aresztowaniu kogoś z NOW-ej. Nawet jeśli wszystko się rozpadnie, dalej będę pisał i sam wystukam na maszynie tekst z trzema kopiami. Cztery egzemplarze przeczyta kilkadziesiąt osób, jeden czy dwa ktoś przechowa. Taka myśl podtrzymuje siły do pisania. Wczoraj dzwonił Marian, że pewna czytelniczka Zapisu po przeczytaniu Miesięcy złożyła na jego ręce 1000 złotych — dla mnie. O nie, z nikim bym się nie zamienił na wydanie masowe”.]. Carnets [Miesiące], $1^{\mathrm{er}}$ avril 1980, [in :] Lawina i kamienie [L'avalanche et les pierres], p. 417.

${ }^{20}$ Traduit du polonais par J.-Y. Erhel, Paris, Gallimard, coll. Arcades, 2003. 
remarque, « chaque homme peut raconter son passé en plusieurs versions, dont aucune ne sera fausse $»$. Aucune ne sera vraie non plus, sans doute... ${ }^{21}$.

Dans tous ces récits, auxquels il faut ajouter Rondo ${ }^{22}$ (1982), c'est la représentation de l'Histoire vue par le prisme d'une vie individuelle qui est mise au premier plan. Brandys écrira toujours des histoires individuelles fictives, intimement mêlées à une trame de faits réels, permettant ainsi au lecteur de se référer à la réalité historique.

En vérité, écrivait Brandys dans ses Carnets, depuis le début il n'existait pour (dans) moi que les deux sujets : 1 . Quand et de quelle manière la réalité devient récit, et le récit réalité ; 2. Est-ce que, ou plutôt jusqu'à quel point, on peut créer sa propre destinée, affranchie de la Providence et de l'Histoire ${ }^{23}$.

En 1993, Brandys est décoré par le ministre français de la culture de l'ordre des Arts et des Lettres. En 1999, le Pen-Club polonais décerne un prix à l'écrivain pour l'intégralité de son œuvre.

\section{Ce mot-là}

Du riche corpus des textes de Brandys (ils ne sont pas tous mentionnés ici), c'est le roman Samson qui sera analysé. En effet, c'est là que Brandys, en témoignant de la condition du Juif essayant de survivre du côté aryen pendant la guerre, commence le long processus de reconnaissance de ses propres origines. Jakub Gold, le héros du livre, et sans doute l'alter ego de Brandys, découvre non pas ses origines — dans sa famille, elles n'ont jamais été dissimulées - mais la vision que les autres ont de lui, celle d'un étranger. Cette découverte signifie pour lui la fin du monde où il se sentait en sécurité.

En effet, la révélation des origines juives coïncide souvent avec la fin de l'enfance et de l'innocence. Elle annonce en même temps l'entrée dans l'âge adulte et dans l'espace inconfortable de la conscience de soi. L'enfant chassé du Paradis éprouve des sentiments contradictoires : étonnement - voire incrédulité -, peur, honte, rejet.

On peut noter au passage que trois écrivains majeurs ont parlé de cet événement crucial de leur vie : Albert Cohen dans $\hat{O}$ vous, frères humains, Janusz Korczak, qui évoque le souvenir du «canari juif» dans son Journal, et Alain Finkielkraut dans Le Juif imaginaire. Si chacun l'a fait à sa manière et dans des circonstances différentes, il n'en reste pas moins que les passages de ces trois ouvrages qui introduisent cette problématique présentent des traits communs. On y assiste en effet à l'initiation et au passage d'enfants ou de jeunes gens vers un autre monde, où rien ne sera plus comme avant, et le mot est enfin prononcé après une longue période de silence, souvent accompagné d'un qualificatif péjoratif (« sale Juif » ou « youpin »).

Jan Błoński n'exagère sans doute pas lorsqu'il affirme que la question des origines juives est à la source des obsessions thématiques de Kazimierz Brandys ${ }^{24}$. Ambiguë

${ }^{21}$ Maria Delaperrière a consacré son article au "moi polyphonique» de Brandys, cf. Kazimierz Brandys ou 'trois fois moi', Les Nouveaux Cahiers franco-polonais 2002 (actes du colloque organisé par l'Université Paris IV-Sorbonne, consacré à Kazimierz Brandys), repris dans son ouvrage La littérature polonaise à l'épreuve de la modernité, Paris 2008, p. 385-398.

${ }^{22}$ Rondo, trad. fr. J.-Y. Erhel, Paris 1989.

23 „Naprawdę istniały dla (we) mnie od początku tylko dwa tematy. 1. Kiedy i w jaki sposób rzeczywistość staje się opowiadaniem, a opowiadanie rzeczywistością; 2. Czy, albo do jakiego stopnia, można stworzyć własne przeznaczenie, niezawisłe od Opatrzności i Historii”. [in:] Miesiace 1985-1987 [Carnets], Paris 1987, p. 144.

${ }^{24}$ Cf. J. Błoński, Autoportret żydowski 1981 [Autoportrait juif 1981], [in :] J. Błoński, Kilka myśli co nie nowe [Quelques pensées qui ne sont pas nouvelles], Cracovie 1985, p. 116;121-122. 
dans Samson, la double identité de l'écrivain devient, surtout dans les années 1960, l'un de ses thèmes privilégiés de réflexion.

Si l'on suit la façon dont la parole brandysienne évoque ce sujet, on s'aperçoit qu'elle est d'abord «cachée » dans le personnage romanesque de Jakub Gold et que l'auteur sème çà et là des signes et des non-dits dans les pages de ses ouvrages postérieurs, qui s'éloignent des formes narratives classiques (Le joker, La place du marché, Le petit livre).

L'histoire de Jakub Gold commence juste avant la guerre. Le héros, issu d'une pauvre famille juive de Łódź, étudiant en droit à l'université de Varsovie, semble être le personnage type du Juif polonais non seulement assimilé, mais certain de la pérennité de son destin sur le sol polonais, bien qu'on lui fasse parfois comprendre, lors des fêtes que ses camarades organisent par exemple, qu'il est « différent ». Débonnaire et naïf, il ne comprend pas les premiers signes qui le condamneront à être l'Autre. Pour l'heure, c'est avec simplicité et sans aucun complexe qu'il répond aux questions d'un agent de police qui l'interroge sur son identité, à la suite d'une rixe après une soirée trop arrosée :

- Vous voulez bien me donner votre nom ?

— Gold. Jakub Gold.

- Votre date de naissance ? Les prénoms de vos parents ? Vous m'excuserez, ce sont de simples formalités.

— 27 octobre 1916. Le prénom de ma mère - Adela. Celui de mon père — Léon, Dieu ait son âme. Il était commerçant, né à P. Toute notre famille est d'ici. [...]

— [...] Désolé, mais il faut que je vous demande quelle langue on parle chez vous.

Vous êtes de confession mosaïque, de nationalité juive, je voudrais savoir, comprenezvous, si votre éducation ...

- Je suis de confession mosaïque, mais de nationalité polonaise. On parle polonais chez nous.

- Bien. Bien. Mais si vous êtes de nationalité polonaise, je ne comprends pas pourquoi vous avez crié dans votre jargon quand on vous a arrêté. En plus, c'étaient des mots insultants pour le peuple polonais.

- Je n'ai pas crié.

— Pourtant il y a des témoins. $[\ldots]^{25}$

Les questions du fonctionnaire de police peuvent ne pas éveiller la vigilance de Gold : elles sont posées sur un ton aimable et sans agressivité.

Il n'en est pas de même dans l'épisode suivant, qui se passe toujours avant la guerre, mais dans un contexte politique différent, après que les slogans antisémites sont devenus chose courante. Un des camarades de classe de Gold, Klemens Jackiewicz, semble adhérer aux idées d'un mouvement politique qui prône notamment le boycott des magasins tenus par des Juifs. La scène se passe pendant un match de football joué dans une cour de récréation ${ }^{26}$. Jakub Gold envoie par erreur le ballon à la tête de Jackiewicz.

25 „- Pańska godność, jeśli wolno wiedzieć? - Gold. Jakub Gold. — Data urodzenia, imiona rodziców? Wybaczy pan, to zwykłe formalności. - 27.10.1916. Matka Adela. Ojciec Leon, błogosławionej pamięci. Kupiec, urodzony w P. Cała rodzina tutejsza. [...] - Bardzo mi przykro, ale muszę pana zapytać, w jakim języku rozmawia się u pana w domu. Pańskie wyznanie jest mojżeszowe, pańska narodowość żydowska, chodzi mi o to, rozumie pan, czy pańskie wychowanie... - Moje wyznanie jest mojżeszowe, ale narodowość jest polska. I mówi się po polsku. - Dobrze. Dobrze. Ale jeśli pańska narodowość jest polska, to w takim razie nie rozumiem, dlaczego pan krzyczał w żargonie, kiedy pana zatrzymano. I to słowa obrażające naród polski. - Nie krzyczałem. - Są przecież świadkowie". Samson, Varsovie 1948, p. 7-8.

${ }^{26}$ C'est dans le même décor d'une cour de récréation qu'Alain Finkielkraut place le début de sa réflexion sur son « apprentissage » d'être Juif. Cf. Le Juif imaginaire, Paris 1980, p. 9-10. 
— Excuse-moi, Klemens ! fit Jakub en riant. Je ne l'ai pas fait exprès.

Jackiewicz fit une grimace, cracha aux pieds de Jakub et dit : Sale youpin ${ }^{27}$.

Élevé dans une famille juive à demi polonisée, où le mythe du prince Joseph coexistait avec la légende de Berek Joselewicz et la légende des Maccabées avec l'histoire de la victoire du roi Jean Sobieski à Vienne, écrit Józef Wróbel à propos de Samson, [Jakub Gold] est rejeté par la communauté polonaise quand les mots " sale youpin » tombent de la bouche de son camarade de lycée $[\ldots]^{28}$.

Gold cherche alors du réconfort et une explication sur ce qui s'est passé auprès de son ami Tolo :

Tolo lui répondit qu'ils [les membres de l'organisation à laquelle appartient Jackiewicz] voulaient libérer la Pologne des Juifs. Cela étonna beaucoup Jakub, qui demanda s'ils voulaient aussi libérer la Pologne de lui, Jakub. Tolo rit : il expliqua qu'il ne s'agissait pas ici d'individus, mais de trois millions de personnes qui constituaient une masse d'étrangers. Mon petit Jakub, ajouta-t-il en baissant la voix, tu me connais, moi, ça m'est égal de savoir qui est Juif, qui est Turc. Mais vous avez quitté votre terre; ce ne serait pas plus raisonnable d'y retourner? [...] Jakub s'étonna de nouveau, car jusqu'alors il n'avait jamais pensé avoir quitté sa terre. [...] Celle-ci n'était-elle donc pas la sienne ? [...] Il n'avait pas d'autre terre que sa maison rue Łąkowa, son école qui portait le nom de Kościuszko, et la forêt au bord de la rivière, où ils allaient en été. Cette terre lui suffisait et il n'en voulait pas d'autre ${ }^{29}$.

Ces deux extraits de Samson, sous leur air ironique et faussement ingénu, sont révélateurs de l'état d'esprit d'un Polonais d'origine juive qui considère la Pologne comme sa «petite patrie». Tout ce qui compose sa terre natale se limite à ce qu'il voit autour de lui, à ce qu'il vit « ici et maintenant», sans se poser de questions sur la légitimité de son appartenance à cette communauté, tellement elle lui paraît évidente, naturelle.

Brandys nous montre un cas emblématique : Jakub Gold devient Juif parce que les autres en décident ainsi ${ }^{30}$. Juif « sartrien », il est en quelque sorte obligé de l'être, et c'est à ce moment crucial de sa vie qu'il épouse, sans en être vraiment conscient et malgré lui, le « destin juif », celui d'un étranger persécuté.

[...] On frappait les Juifs dans la rue en plein jour, et personne ne les défendait... Pire encore, il semblerait que d'honnêtes gens étaient d'avis que, pour leur bien commun,

27 „- Przepraszam, Klemens! — roześmiał się Jakub — nie chciałem! — Jackiewicz skrzywił się, strzyknął śliną pod nogi Jakuba i powiedział: Parch”. Samson, p. 16.

28 „Wychowany w na wpół spolonizowanej rodzinie żydowskiej, w której mit księcia Józefa współistniał z legendą Berka Joselewicza, podanie o Machabeuszach z historią wiktorii króla Jana Sobieskiego pod Wiedniem, [Jakub Gold] odrzucony zostaje przez polską społeczność słowem "parch", które pada z ust gimnazjalnego kolegi...". [in :] J. Wróbel, Tematy żydowskie w prozie polskiej 1939-1987 [Thèmes juifs dans la prose polonaise 1939-1987], Cracovie 1991, p. 14.

${ }^{29}$ „Tolo odpowiedział, że oni chcą uwolnić Polskę od Żydów. Jakub zdziwił się i zapytał, czy od niego, Jakuba, także chcą Polskę uwolnić. Tolo roześmiał się: wytłumaczył, że nie chodzi o jednostki, ale o trzy miliony ludzi, którzy stanowią obcą masę. - Jakubku - dodał ciszej ty wiesz, że mnie wszystko jedno, kto Żyd, a kto Turek. Ale przecież wyście opuścili swoją ziemię i czy to będzie źle, jeśli tam powrócicie? [...] Jakub znowu się zdziwił, bo dotąd nie przyszło mu do głowy, że opuścił swoją ziemię. [...] Czy to nie była jego ziemia? [...] Przecież nie miał innej ziemi prócz domu na Łąkowej, szkoły imienia Kościuszki i lasu nad rzeką, gdzie jeździli latem. Wystarczała mu ta ziemia i wcale innej nie pragnął”. Samson, p. 19.

${ }^{30}$ Remarquons que le choix du nom Gold (« or » en allemand et en yiddish) est révélateur : c'est presque un nom commun et non un nom propre, compte tenu de l'association communément faite entre les Juifs et l'argent. 
les Juifs devaient quitter le sol polonais. Jakub commençait à comprendre que personne n'avait besoin de lui ici et que lui, Jakub Gold, était le seul à considérer la Pologne comme sa patrie ${ }^{31}$.

C'est ainsi que l'enfance de Jakub Gold prit fin ${ }^{32}$.

En effet, Jakub est arrêté et condamné à dix ans de prison pour avoir, en état de légitime défense, tué un étudiant qui l'attaquait avec une pierre lors d'émeutes antisémites à l'université de Varsovie. En prison, il fait la connaissance de membres du parti communiste, illégal à l'époque. L'agitation dans la prison où il est détenu lui permet de recouvrer la liberté (relative, certes...) le $1^{\text {er }}$ septembre 1939, lorsque la guerre éclate.

Avant l'apocalypse, Jakub Gold a perdu une partie de ses illusions, mais la guerre et l'occupation de la Pologne achèvent de lui ôter ce qui lui restait de son enfance. Il est désormais définitivement stigmatisé et ces stigmates sont ceux de beaucoup de Juifs pendant la guerre, quand un nom et une apparence physique signifiaient la condamnation à mort. Dans le roman de Brandys, ces « signes particuliers » sont exposés par l'opposition du noir et du blanc. Des yeux et des cheveux noirs signifiaient un danger de mort, tandis qu'un regard clair et une chevelure couleur de blé plaçaient les gens du côté de la vie, si précaire fût-elle. La frontière était nettement tracée, comme celle du mur du ghetto.

[...] Tu viens de te regarder dans la glace, Jakub, tu as bien vu, non? Nous sommes de l'autre côté du mur, Jakub. Ici, on chasse les Juifs comme des lapins. [...] Regarde ton visage. [...] Jakub se retourna vers le miroir et regarda à nouveau son visage. Il devait reconnaître au fond de lui-même que ses lèvres étaient grosses et foncées, que ses yeux exorbités avaient l'éclat des olives noires, et que ses cheveux étaient épais et bouclés comme le manteau de fourrure que les Allemands avaient pris à Madame Rozen. — Tu vois ton front? dit Gienio. [...] Il n'y a que les Juifs qui ont les cheveux plantés si bas. [...] Et puis, est-ce qu'un Polonais peut avoir le teint aussi mat, en plein hiver, alors qu'on ne peut pas aller bronzer au bord de la Vistule ? Lucynka a dit que des comme toi, il n'y en a plus de ce côté-là, et que même les gosses ne te laisseraient pas passer dans la rue. "Ce visage, a-t-elle dit, va le perdre, et va nous perdre aussi". Tu le comprends, Jakub? Par les temps qui courent, un visage comme ça, c'est comme la peste. [...] Si tu t'occupes de quelqu'un, tu le condamnes à mort, ton amitié pour quelqu'un signifie la mort ${ }^{33}$.

31 , [...] Żydów bito na ulicy w biały dzień i nikt się za nimi nie wstawiał... Co gorzej, podobno ludzie porządni twierdzili, że dla wspólnego dobra Żydzi powinni opuścić polski kraj. Jakub powoli zrozumiał, że nie jest tu nikomu potrzebny i że jedynym człowiekiem, który uważa, że Polska to jego ojczyzna, jest on sam, Jakub Gold”. Samson, p. 53.

32 "Tak skończyło s i ę dzieciństwo Jakuba Golda”. Samson, p. 35.

33 „Przecież przed chwilą patrzyłeś w lustro, więc chyba wiesz. Jesteśmy po drugiej stronie muru, Jakub. Tu Żydów łapią jak zające. [...] Spójrz na swoją twarz. [...] Jakub odwrócił się do lustra; znów zobaczył swoją twarz. Musiał przyznać w duchu, że jego wargi były grube i ciemne, oczy wypukłe, o połysku dojrzałych oliwek, a włosy tak skręcone i gęste jak karakułowe futro pani Rozen, które zabrali Niemcy. — Czy widzisz, jakie masz czoło? — mówił Genio. [...] Tylko Żydzi maja czoła tak nisko zarośnięte. [...] A który Polak ma taką śniadą cerę, w zimie, kiedy nie chodzi się nad Wisłę? Lucynka powiedziała, że takich jak ty nie ma już po tej stronie i że małe dzieci nie dałyby ci przejść ulicą. 'On zgubi swoją twarzą - mówiła - siebie i nas'. Czy ty rozumiesz, Jakub? Taka twarz to dzisiaj zaraza dla wszystkich. [...] Twoja opieka to śmierć, twoja przyjaźń to śmierć...”. Samson, p. 125-126. 
Jakub Gold refuse pourtant son « destin juif». Il prend part aux combats contre les Allemands en septembre 1939, est enfermé ensuite dans le ghetto, mais décide de passer du côté aryen après la mort de sa mère. Conscient du danger qu'il fait courir aux Polonais qui le cachent, il ne veut pas mourir à cause de ses origines. La seule communauté où il se sent à égalité avec les autres et en sécurité est celle des résistants (sans doute de gauche) pour qui le fait qu'il soit Juif est apparemment sans importance :

Si tu veux être avec nous - la voix de Pankrat était calme — reste. Ici, dans cet appartement, peu importe le visage qu'on a. Au moment où ils entreront ici, tous ceux qu'ils rencontreront périront. Sur place ou plus tard. Peu importe qui on est. Dans cet appartement, on ne te tuera pas parce que tu es Juif. Celui qui est d'accord pour être avec nous perd ses signes particuliers et devient simplement l'un des nôtres ${ }^{34}$.

Reste le problème du pseudonyme, qu'il lui faut maintenant choisir. Après avoir longtemps hésité, il décide de s'appeler Samson, malgré la réticence de ses camarades qui, sans doute pour des raisons de clandestinité mal comprises par Jakub-le naïf, auraient préféré un nom à consonance plus « slave ».

Ce pseudonyme est lourd de sens. En effet, Samson était, selon la Bible, un héros d'Israël doté d'une force surhumaine. Comme sa mère était stérile, il était né de la volonté divine, pendant l'occupation de son pays par les Philistins, qui dura quarante ans. Sa puissance était cachée dans ses cheveux. Lorsqu'il tomba amoureux de Dalila, celle-ci trahit son secret aux princes philistins et lui coupa les cheveux pendant son sommeil. Malgré cela, Samson réussit, grâce à ses cheveux repoussés à détruire le temple philistin, mais il périt avec ses ennemis.

Telle fut aussi la fin de Jakub Gold. Il mourut en lançant des grenades lors d'un combat inégal avec les Allemands.

Ainsi, Jakub, en choisissant le nom de Samson, veut à la fois incarner la résistance (tout comme le Samson de la Bible était le symbole de la résistance contre les Philistins), forcer le destin (il ne se laissera pas entraîner à la mort « comme un mouton à l'abattoir »), et last but not least, ne pas oublier ses origines, voire les proclamer en choisissant un tel nom de guerre.

Samson n'a pas été analysé de façon approfondie par les critiques, qui soulignèrent notamment le caractère simpliste des personnages.

Dans Samson - écrit Agnieszka Czyżak - pour laquelle c'est un ouvrage «schématique et tendancieux», se manifestent un déterminisme social extrême et le psychisme simpliste des protagonistes créés par l'auteur.

Le critique refuse au héros principal « sa dimension héroïque » puisque

[...] le destin d'un homme persécuté pendant la guerre en raison de son existence équivalait à la négation de la notion même de choix [...]. Le lien allégorique avec le personnage biblique de Samson est devenu un moyen simpliste de mener la narration ${ }^{35}$.

34 „Jeżeli chcesz być z nami — usłyszał spokojny głos Pankrata — to zostań. Tutaj, w tym mieszkaniu, już dawno nie ma znaczenia, kto jaką ma twarz. Z chwilą gdy tutaj wejdą, każdy, kogo spotkają, musi zginąć. Na miejscu albo później. Bez względu na to, kim jest. W tym mieszkaniu nie zabiją cię za to, że jesteś Żydem. Ten, kto godzi się być z nami, traci swoje znaki szczególne i staje się tylko jednym z nas”. Samson, p. 213.

35 „Skrajny determinizm społeczny, a co za tym idzie uproszczenie psychiki bohaterów, najwyraźniej doszedł do głosu w Samsonie [...]. Wojenny los człowieka prześladowanego za swoje istnienie równał się przekreśleniu samego pojęcia wyboru [...]. Alegoryczne nawiązanie do 
Samson est cependant sans conteste un récit très significatif pour qui veut étudier le «complexe polono-juif » chez Brandys. Certes, le roman peut paraître simpliste, montrant le destin type d'un Juif polonais juste avant la guerre et sous l'Occupation. C'est un portrait presque trop «parfait» et empreint effectivement d'un certain manichéisme : Jakub Gold, bon, juste, naïf, honnête versus un monde ennemi, hostile et truffé de dangers. Malgré quelques personnages de «bons » Polonais prêts à l'aider au risque de leur vie (et de femmes follement amoureuses de lui...), Gold voit son univers restreint par la force des choses à une cave, à une cachette dans une armoire, à un trou dans un mur. Il en devient un personnage stéréotypé.

Le caractère « simpliste » de la narration ne réside pas cependant dans le fait que Gold correspond au cliché traditionnel du Juif. Bien au contraire, Gold choisit son destin en bravant l'évidence de sa condamnation à mort. Ce choix est de taille : il consiste à refuser sa condition de Juif, et la mort certaine qui en résulte. Il le fait de deux manières : d'abord en s'alliant à un groupe de résistants, ensuite en décidant de la manière dont il mourra. En effet, comme il a été dit, le seul endroit, quoique clos, où Gold se sente bien, c'est la «planque» dans laquelle sont imprimés des journaux clandestins et planifiées des « actions » contre les Allemands. Il la préfère au ghetto, où il refuse de retourner. Bien que rien ne l'indique clairement, tout porte à croire que l'organisation de résistants qui accueille Gold comme un des siens (n'était-ce léger différend concernant son pseudonyme...) est d'obédience communiste, en tout cas, de gauche. Il s'agit probablement du Parti ouvrier polonais [Polska Partia Robotnicza, $\mathrm{PPR}]$, futur parti dirigeant dans la Pologne de l'après-guerre.

La date, décembre 1947, que l'auteur inscrit au bas de la dernière page de Samson suggère que cette vision manichéenne résultait de la nécessité de satisfaire aux consignes officielles. Il n'en reste pas moins que des organisations de la mouvance communiste, dès avant la guerre, affichaient dans leur programme l'internationalisme, l'abolition des persécutions des minorités ethniques, l'égalité des races, etc. Les Polonais d'origine juive ayant des convictions laïques étaient naturellement attirés vers ces mouvements, qui manifestaient officiellement leur désintérêt pour «la question juive » (à la différence de la droite, souvent ouvertement antisémite). «Un Juif, en devenant communiste, cesse d'être Juif», disait un autre écrivain polono-juif, Julian Stryjkowski. L'entrée dans un mouvement communiste était donc l'un des moyens pour qui voulait quitter, tant symboliquement que concrètement, le shtetl et son ambiance de repliement.

Ainsi, s'il est possible que Brandys se soumet, dans la construction de son texte, aux exigences des autorités communistes ${ }^{36}$, il n'en décrit pas moins le processus au terme duquel tant de Polonais d'origine juive ont adhéré aux idées communistes dans la Pologne de l'après-guerre.

Le deuxième choix délibéré de Gold — mais est-il très éloigné du premier ? — est la façon dont il décide de mourir. Non pas passivement, en Juif «typique », mais en combattant, en résistant. Dans cette décision, deux fils directeurs s'entrelacent : d'un côté, l'ambition et la volonté de Gold d'être considéré comme le citoyen polonais qu'il était et, de l'autre, la légende de Samson, grand héros du peuple élu, tirée de l'Ancien Testament et dont Jakub parlait avec sa mère.

Samsona biblijnego zmieniło się w uproszczony chwyt fabularny”. A. Czyżak, Kazimierz Brandys, p. 19-20.

${ }^{36}$ Notons que ce texte témoigne tout de même d'une liberté donnée encore à l'époque aux artistes qui traitaient « le sujet juif ». 
S'il est plus que légitime d'accorder une attention soutenue à Samson, un des premier livres-témoignages sur la Shoah écrits après la guerre, il est également intéressant de l'analyser sous l'angle du thème juif, récurrent dans toute l'œuvre de Kazimierz Brandys. En effet, ce texte semble contenir nombre d'éléments qui resurgiront plus tard et qui définiront la difficile (auto) acceptation d'une polonité différente de celle des autres, des « vrais » Polonais.

Pour l'heure, il semble que Brandys ait besoin du contrôle que lui offre la forme romanesque traditionnelle. Il va jusqu'à abuser de diverses incises dans lesquelles il commente, à la première personne et en vrai maître de son récit, les événements et ajoute des explications quant au déroulement de l'action et aux caractéristiques des personnages. Pourtant, ce «je», parce qu'extradiégétique, est aussi éloigné que possible du narrateur : c'est un moyen qui permet à Brandys de souligner la distance qui le sépare du protagoniste. De même, la neutralité du « il» dans Samson apparaît comme un garde-fou qui empêche l'auteur de s'identifier au protagoniste. Malgré les quelques similitudes biographiques entre Brandys et Jakub Gold - la date de naissance de Gold donnée au début du roman correspond exactement à celle de l'auteur la forme de ce récit permet une distanciation certaine et éloigne la douloureuse question des origines juives de l'écrivain, en la reléguant dans l'espace de la littérature et donc de la fiction.

C'est justement cette neutralité du «il» dans Samson qui retiendra toute notre attention.

Le «il» narratif — écrit Maurice Blanchot — qu'il soit absent ou présent, qu'il s'affirme ou se dérobe, qu'il altère ou non les conventions d'écriture [...] marque ainsi l'intrusion de l'autre dans son étrangeté irréductible, dans sa perversité retorse. L'autre parle. Mais quand l'autre parle, personne ne parle, car l'autre [...] n'est précisément jamais seulement l'autre, il n'est plutôt ni l'un ni l'autre, et le neutre qui le marque le retire des deux, comme de l'unité, l'établissant toujours au-dehors du terme, de l'acte ou du sujet où il prétend s'offrir. La voix narrative [...] tient de là son aphonie. Voix qui n'a pas de place dans l'œuvre. [...] Le « il » est plutôt comme un vide dans l'œuvre ce mot-absence qu'évoque Marguerite Duras dans l'un de ses récits, « un mot-trou, creusé en son centre d'un trou, de ce trou où tous les autres mots auraient dû être enterrés », et le texte ajoute "On n'aurait pas pu le dire, mais on aurait pu le faire résonner - immense, sans fin, un gong vide...». C'est la voix narrative, une voix neutre qui dit l'œuvre à partir de ce lieu sans lieu où l'œuvre se tait ${ }^{37}$.

Malgré cette neutralité du « il », le thème juif resurgit fortement dans Samson où Brandys, nolens volens, commence son jeu avec l'autofiction. Nonobstant l'évidence de la problématique abordée, ce texte est en fait un grand cri muet, un livreabsence au sens durassien du terme, car l'essentiel est passé sous silence. Le héros est en même temps quelqu'un et personne, tellement son histoire est emblématique et en quelque sorte « commune ». De ce fait, il perd, paradoxalement, toute identité propre, « il » disparaît, laissant un vide, un non-dit. Mais tout aussi paradoxalement, c'est cette absence qui progressivement mènera l'écrivain à la plénitude.

À partir des années 1960, Brandys change radicalement sa forme de narration. Le roman traditionnel écrit à la troisième personne, avec un narrateur omniscient et omniprésent et aux ambitions « totalisantes », cède la place aux textes autothématiques et aux formes narratives hybrides et autofictionnelles. Il serait intéressant d'observer le passage du personnage de Jakub Gold au « je » dans des livres comme Le joker, 1966,

${ }^{37}$ M. Blanchot, De Kafka à Kafka, Paris 1981, p. 181-182. 
La place du marché, 1968, et surtout Le petit livre, 1970. Remarquons donc qu'il faudra attendre les deux derniers récits de Brandys ${ }^{38}$, De mémoire...,1995 et Les aventures de Robinson, 1999, pour que le tabou soit totalement levé et la liberté d'être soi-même entièrement acquise ${ }^{39}$. Pour de multiples raisons, tant idéologiques que personnelles, en 1947, Brandys préfère se cacher derrière ses personnages.

\section{BIBLIOGRAPHIE}

A. Bikont, J. Szczęsna, Lawina i kamienie. Pisarze wobec komunizmu, Varsovie 2006 ;

M. Blanchot, De Kafka à Kafka, Paris 1981 ;

J. Błoński, Autoportret żydowski 1981, [in:] J. Błoński, Kilka myśli co nie nowe, Cracovie: 1985 ;

A. Czyżak, Kazimierz Brandys, Poznań 1998 ;

M. Delaperrière, Kazimierz Brandys ou «trois fois moi », Les Nouveaux Cahiers franco-polonais $2002 \mathrm{n}^{\circ} 1$

—, La littérature polonaise à l'épreuve de la modernité, Paris 2008 ;

R. Nycz, Parodia i pastisz. Z dziejów pojęć artystycznych w świadomości literackiej XX wieku. Uwagi o pastiszu, [in:] R. Nycz, Tekstowy świat. Poststrukturalizm a wiedza o literaturze, Cracovie 2000 ;

Pisarze polsko-żydowscy XX wieku. Przybliżenia, M. Dąbrowski, A. Molisak (dir.), Varsovie 2006 ;

«Wariacje pocztowe » Kazimierza Brandysa, I. Iwasiów, J. Madejski (dir.), Szczecin 1999 ;

M. Wołk, Tekst $w$ dwóch kontekstach. Narracja pierwszoosobowa w powieściach Kazimierza Brandysa, Torun 1999 ;

J. Wróbel, Tematy żydowskie w prozie polskiej 1939-1987, Cracovie 1991.

${ }^{38}$ Pour être plus précis, le tout dernier livre de Brandys - un ensemble d'essais publiés auparavant dans le journal Gazeta Wyborcza - a paru après sa mort. Cf. Co nie jest prawda. Notatki z lektur i z życia [Ce qui n'est pas vrai. Notes des lectures et de la vie], Varsovie 2003.

${ }^{39}$ La mise en parallèle des extraits du Petit livre et des Aventures de Robinson concernant le même épisode de l'enfance de Brandys est à ce titre révélatrice: "C'est alors que Pola [association facile avec Polka-Polonaise], sans se retourner vers moi, lui cria quelque chose. Il s'immobilisa. [...] Elle avait crié d'une voix grêle et tremblante, ses mots m'atteignirent comme à retardement, j'étais pétrifié. [...] Pola, murmurai-je en esquissant un sourire. Va-t'en, bredouilla-t-elle, espèce de ... Et elle répéta le mot. C'est alors que, dans une lueur de lucidité soudaine, je compris, je saisis, je me rappelai ! Oui, c'était bien le même mot! J'en étais sûr. C'était le mot qu'avait crié la mendiante en maudissant mon père. Malédiction ou juron, c'était une syllabe magique condamnant un être humain à une différence honteuse, en en faisant quelqu'un ou quelque chose d'autre...». [,Wtedy Pola, nie odwracając się w moją stronę, krzyknęła coś do niego. Znieruchomiał. [...] Krzyknęła to cienkim, rozdygotanym głosem, jej słowa utkwiły we mnie z opóźnieniem, ale ja także zmartwiałem. [...] - Polu... - szepnąłem próbując się uśmiechnąć. — Odejdź - mruknęła - ty... I powtórzyła to słowo. I wtedy nagle w jasnowidzącym błysku świadomości zrozumiałem, pojąłem, przypomniałem sobie. Tak, to było to samo! Na pewno. To samo słowo, którym żebraczka przeklęła mego ojca. Zaklęcie czy przekleństwo, magiczna sylaba skazująca ludzką istotę na haniebną odmienność, przemieniająca ją w kogoś lub w coś innego...”]. Mała księga [Le petit livre], Varsovie, 1970, p. 41-42. « [...] je suis né dans une famille polonisée depuis longtemps, mais malgré cela, au parc Sienkiewicz, lorsque j'avais sept ans, une petite fille dont j'étais amoureux, avait crié en s'adressant à son frère : 'Ne joue pas avec ce Juif !' ». " [...] przyszedłem na świat w rodzinie od dawna spolonizowanej, ale mimo to w Parku Sienkiewicza, gdy miałem siedem lat, dziewczynka, w której byłem zakochany, zawołała do swojego braciszka: 'Nie baw się z tym Żydem!' ». Przygody Robinsona [Les aventures de Robinson], Varsovie 1999, p. 71-72. 


\section{KAZIMIERZ BRANDYS'S PSEUDONYMS}

The author of the article first introduces Kazimierz Brandys through his oeuvre, life choices and political stance. Next, she focuses on the analysis of his novel Samson (1948), which is the writer's first step in the long road leading to his acceptance and disclosure of his Jewish roots, as well as a double Polish-Jewish identity.

KEY WORDS: Kazimierz Brandys; Polish Jews; Samson; World War II; German occupation of Poland; identity; communism.

\section{PSEUDONIMY KAZIMIERZA BRANDYSA}

Artykuł w pierwszej części przedstawia sylwetkę, utwory, wybory życiowe i polityczne Kazimierza Brandysa, następnie skupia się na analizie jego powieści Samson (1948), która rozpoczyna długą drogę autora do akceptacji i ujawnienia korzeni żydowskich i podwójnej polsko-żydowskiej tożsamości.

Słowa kluczowe: Kazimierz Brandys; polscy Żydzi; Samson; wojna; okupacja; tożsamość; komunizm. 